\title{
TÉCNICAS ANESTÉSICAS DESTINADAS À CIRURGIA OCULAR NO CÃO
}

\author{
ANESTHESIC TECHNIQUES IN OCULAR SURGERY IN DOGS
}

Newton NUNES': José I uis I AUIS2

\begin{abstract}
RISSUM()
-()s autores apresentam. de forma cotejativa, procedimentos anestésicos destinados a manobras cirúrgicas intra e extra-oculatres no cão. Para tanto, discutem alternativas práticas e exequíveis, destinadas a atualizar algueles que militam nals especialidarles de anestesiologia e/ou oftalmologia. Amontam técnicas em anestesia geral. dissociativa e procedimentos outros. Tecem consideraçôes acerca de características relativas à posição do bulbo ocular. diâmetro pupilar, pressấo intratocular e rellexos óculo-palpebrais. Apentam para técnicas de indução, bem como para vantagens do monitoramento do paciente.
\end{abstract}

CNITERMOS: Anestesiat: Cirurgia ocular; Cäles

\section{INTROIDUÇÃO}

Com o desenvolvimento da oftalmologia no ambito da Medicina Veterinária. deu-se início a diversas práticats clínico-cirúrgicas, obrigando an desenvolvimento ou aprimoramento de técnicas anestésicas específicas. com vistas não só a aumentar a margem de segurança para o paciente. como também a aluxiliar o cirurgião. produzindo campos cirúrgicos favorecedores à condução de procedimentos operatórios. Com a finalidade de atualizar o profissional que se dedica à of talmologia veterinária ou àcuele especializado na administração de lécnicas anestésicas diversas. notadamente na espécie canina. são tecidas, ao longo deste texto, considerações relativats aos procedimentos anestésicos próprios às cirurgias intra e extra-oculares no cão. Motivaram. igualmente. a realização desta apresentação. a escassez de dados e monografias atualizadas pautando o tema.

\section{CONSIDERAÇÕES GERAIS}

Independentemente da natureza da cirurgia oflálmica, parece fundamental a imobilidade completa do paciente, exceto naqueles casos em que o trauma cirúrgico é de menor monta. como por exemplo a remoção de corpos estranhos à córnea. quando a instilação de anestésico local é suficiente.

Na maioria absoluta das cirurgias extra-oftálmicas, as técnicas destinadas à produção de anestesia geral podem ser consideradas adequadas, exceção feita à manutenção anestésica com a quetamina ou tiletamina, pois trata-se de agentes dis- sociativos cuja principal característica é a manutenção dos reflexos protetores do animal (MASSONE2. 1988). entre eles o palpebral. Depreende-se daí a impossibilidade de incidir em campo cirúrgico "reativo". apesar da imobilidade do paciente e do clevado grau de analgesia obtido. Embora a maioria destas cirurgias consistam de correções de oftalmopattias associadas aos anexos do aparelho da visão. devese atentar para a incidência elevada de enucleações do globo ocular. Nestes casos causa alpreensão a bradicardia provocalda pelo reflexo óculo-cardíaco. advindo da tração da musculatura extra-ocular. notadamente o músculo reto medial (MILLER3. 1981). O eleito pode ser compensado com a administração prévia de sulfato de atropina $(0,044 \mathrm{mg} / \mathrm{kg})$. por via intramuscular ou. igualmente. pela manipulação cuidadosa no campo cirúrgico.

As anestesias destinadas aos procedimentos intra-oculares devem ser estudadas mais amiúde. pelo fato de a monitoração do plano anestésico. neste caso, estar prejudicada. A manipulação cirúrgica causa alteraçōes sistêmicas e há. ainda. o risco de perda total da visão sob determinadas condiçōes. por exemplo o aumento brusco da pressĩo intraocular (PIO).

Neste particular, pole-se afimar que a maioria dos agentes empregados em anestesia diminui a PIO, exceção feila a quetamina e tiletamina. cujo uso, por via intravenosa, na induçāo anestésica. pode ser adequado, porém jamais devem ser usados na manutenção da anestesia. 


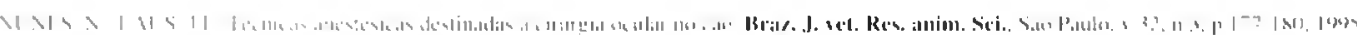

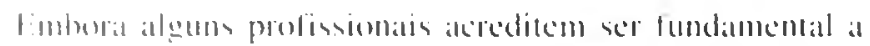

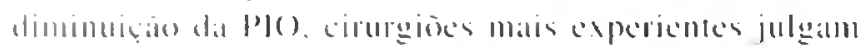

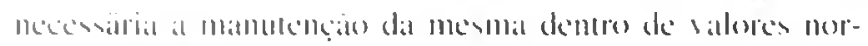

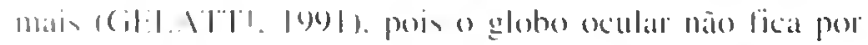

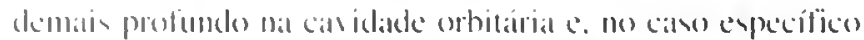

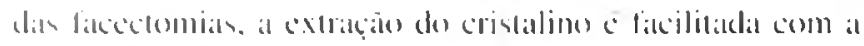
Plo (om niscis momats.

\section{CARACTHEISTICAS DLSEJIV VEIS}

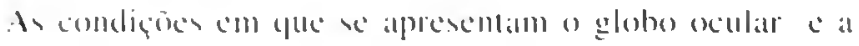
pupila var fundamentais an bom andamento das cirurgeias

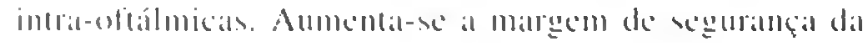

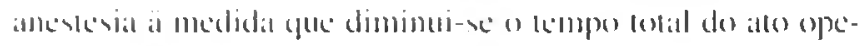

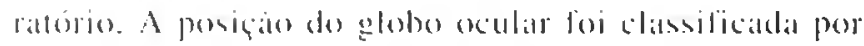

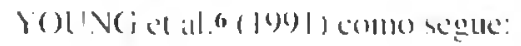

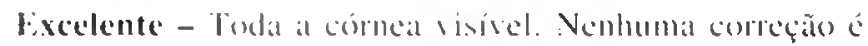
necendirial.

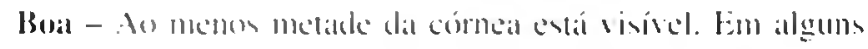
cansos ponter de "reparro" na excelera podem ser necessários.

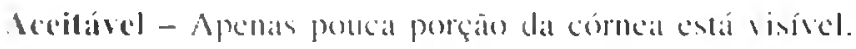

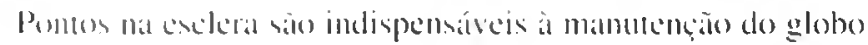

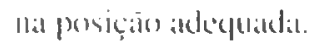

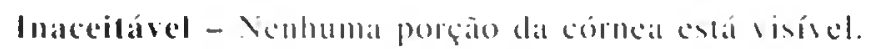
Membanat nictitante prominente.

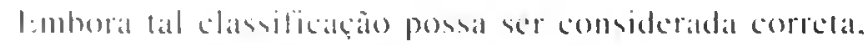

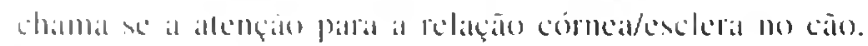

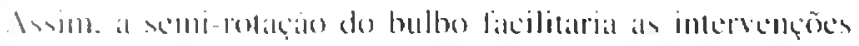
Imrat aculare

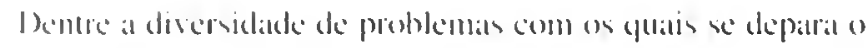

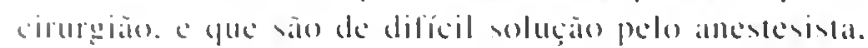

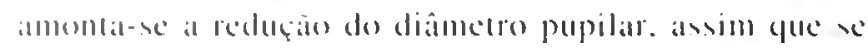

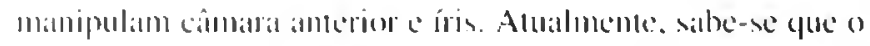

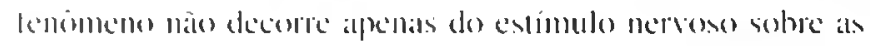

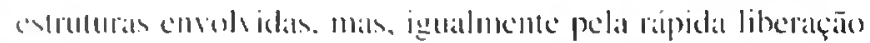

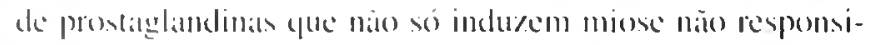

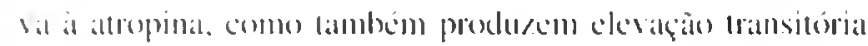

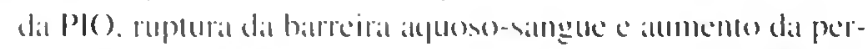

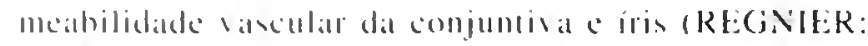

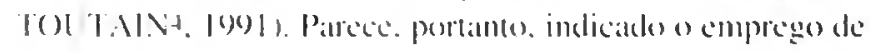

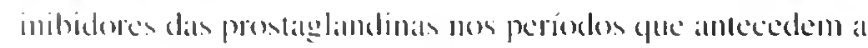

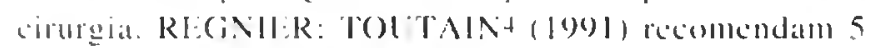
dones orais de 30 me/ke de acido actril-sillicilico a cada 8 horan ou mesmo 1.1 a $2.2 \mathrm{mg} / \mathrm{kg}$ de lluniximmeglumine. por viat intratenosat. incediatamente antes de se inciarem os proecoulos allkentisicus.
() diamemo pupilan deve ser a maior possivel. A cicloplegia perde ser obetida pelo tratimento presio do amimal com

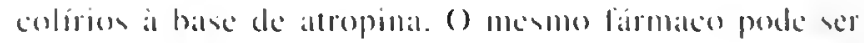
administrado momentor anter dat cirtugeia por via intramucular na done de $0.04+$ mg/he.

Outra variante parad ex produrer dilatação pupilar implica a

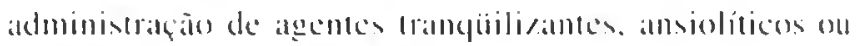

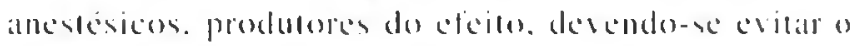

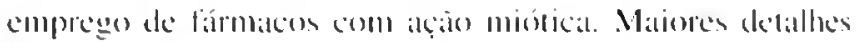

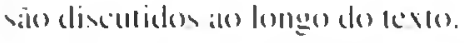

\section{MONITOR A.MENTO DOO PII (ILATI:}

A ahoolula matoria das ancestesals sabo monitoradals. com relaçate a profundidade do plano ancestésico. atranes da

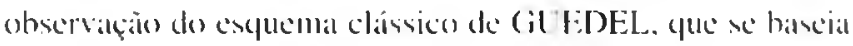
principalmente na posiçäo do gloho oculalr e no diametro pupilar. lomando impossísel o controle dat anestesia pelor rellexor óculo-palpebrais em cirurgias oftálmicass.

Anesevistas menos experientes podem pretender o controle da profundidade ancestésican attanés das frequiênciar cardiacal e respirattoria. expuecendo-se que o ritmo cardíaco é dependente de outros lattores que não só al concentraçāa plastrmática de ancestésico. mormente ent ciruregias intra-oculares. e que

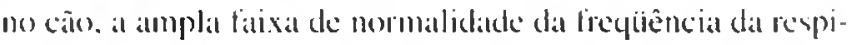

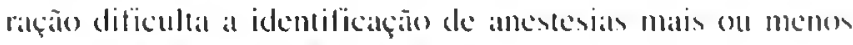
profundas pela simples observaçaio do pariuncetro.

() mélodo adequado ato controle da profundidade anesésica

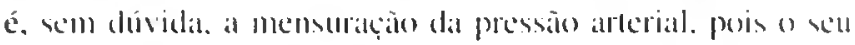
valur é incrementado sempre que oplatmo ancestésicos se tormat mais superficial e dimimuido a medida que se aprofiundat al

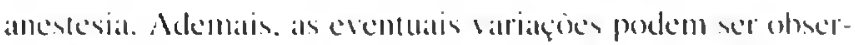

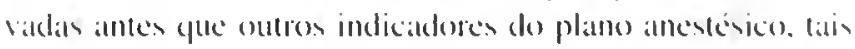

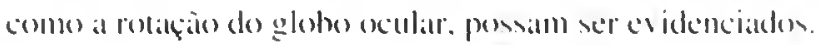

A liequiéncia cardiaca deve ser vista comon dado adjutorio an controle dat profundidade annestesical. Sual mensuraçäe dexe

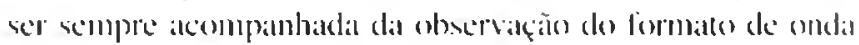

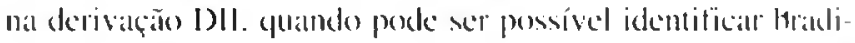
cardial advinda do reflexo iculo-candiatero on de arrilmias ventriculares associadas ato emprego de fámatcos como a

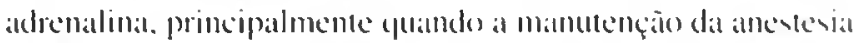

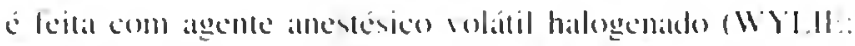

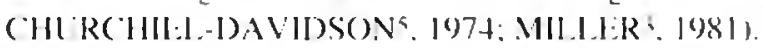

\section{MLDICAÇÃO PRË-INESTÉSICA}

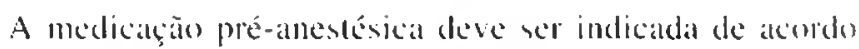
com o estado clinico do paciente e dan caracteristicas interenter an retlexo pupilar desciado. 
Em pacientes hígidos permite-se o emprego da levomepromazina ou clorpromazina na dose de $1 \mathrm{mg} / \mathrm{kg}$ ou acepromazina $(0.1 \mathrm{mg} / \mathrm{kg})$, por via intravenosa, associada ou não ao midazolan. na dose de $0.3 \mathrm{mg} / \mathrm{kg}$. pela mesma via. Em animais cujas condições clínicas nào favoreçam. aconselha-se evitar fenotianínicos. Neste caso, pode-se empregar o diazepam na dose de $1 \mathrm{mg} / \mathrm{kg}$. por via intravenosa. atentando para a produção de midríase subsequiente.

Em quaisquer condiçōes evita-se a xilazina. pois a droga é produtora de bradicardia. que se adicionada às consequiências do reflexo óculo-cardiaco pode delerminar complicaçoes importantes an paciente. Por outro lado, o tármaco é potente produtor de miose (MASSONE? 1988) tornando-se. portanto, inadecuado em procedimentos intra-oculares.

\section{INDUÇÃO}

Apesal de elevarem a PIO. a quetamina e a tiletamina podem ser empregadas na indução da anestesia geral. descle que sejam observadas a via intravenosa e as doses mínimas recomendadas. Com a lécnica observa-se aumento transitório da PIO. que tende à normalidade. decorridos aproximadamente 10 a 15 minutos (WYLIE: CHURCHILDAVIDS(ONS. 1974), (cmpo estes suficiente para a entubaçãa) endotraqueal e o estabelecimento do plano anestésico adequado. Procedendo-se desta forma, ao iniciar o ato operatório o cirurgião deparar-se-á com uma PIO próxima à normal. Ao acrescer-se a estes efeitos grau razóvel de midríase. obtido com o uso de agentes dissociativos. deduzse que a indução com tais fármacos favorece o ato cirúrgico. sendo. portanto, aconselhada.

A indução com o emprego de harbitúricos produz queda da PIO (MILLER? 1981), além de miose puntiforme, embora pouco persistente (WYLIL; CHLRCHILL-DAVIDSON5. 1974). Como estas drogas produzem tardiamente queda da pressão arterial (MASSONE2. 1988), pode-se inferir dificuldade na recuperação do valor basal da PIO. Por estas considerações, recomenda-se evitar barbitúricos na indução da anestesia destinadat a manobras intra-oculares. embora nas extra-oculares seu uso seja indicado.

Permite-se recorrer ao emprego de agentes anestésicos voláleis, associados ou não ao óxido nitroso na indução anestésica. Deve-se. entretanto, observar que tais técnicas só são passíveis de realização em paccientes menos refratários à contenção. ou nacpueles mais sensíveis à medicação préanestésica. A vantagem do método é que além de matior margem de segurança para o paciente. pode-se atribuir ao óxido nitroso midríase em grau dependente da cyantidade de gás administrado na mistura.
O esquema abaixo ilustra al técnica adequada à indução com emprego de $\mathrm{N}_{2} \mathrm{O}, \mathrm{O}_{2}$ e ancstésico volátil.

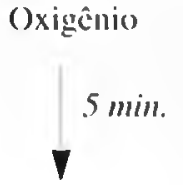

()xigênio $(30 \%)$

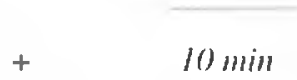

Óxido Nitroso (70\%) ()xiĝ̣nion

$+$ Anestésico volátil

$4.5 \mathrm{~min}$

Oxigênio (30\%) Oxido Nitroso $(70 \%)$ $+$

Anestésico volátil
Com a administração inicial de 02 puro, durante 5 minutos. é possivel eliminar o nitrogênio do circuito anestésico e do "espaço morto" fisiológico. além de possibilitar que o paciente se acostume à presença da máscara pouco impreggnada de odores estranhos ou irritantes.

() fornecimento, em seguida, do $\mathrm{N}_{2} \mathrm{O}$ permite obter narcose o suficiente para que o animal admita o agente volátil. Nesta etapa, já se observa midríase. Devido ao formecimento de (), em concentração superior à do at atmosférico. a midríase não pode ser imputada à hipóxia cerebral relacionada ao) Uso isolado do protóxido de nitrogênio (WYLIE: CHURCHIL_..DAVIDS( NN5, 1974).

Com relação alo agente volátil a ser empregado. pode-se optar por quaisquer das drogas disponíveis no arsenal anestésico, exceção feita ao éter dietílico. por seu poder irrilante para mucoses. difïcultando a accitação pelo paciente. Por outro lado. o fármaco apresenta elevado coeficiente de solubilidade no sangue. o que determina períodos de indução e recuperação prolongadalos (MASSONE?. 1988).

Parece evidente o fato de que. ao optar pela indução com agente volátil, a droga escolhida para a manutenção da anestesia deverá ser a mesma.

\section{MANUTENÇ̃̃o}

Por motivos já explicitados, torna-se impraticável a manutenção da anestesia com agentes dissocialtivos. Outrossim. desaconselhatse o emprego de barbitúricos. Resta, portanto, a opção do emprego de agentes voláteis.

A ação destes fármácos, notadamente os halogenados, sobre a PIO. implica na diminuição dos seus valores basais. () isoflurano. contretanto, por produrir gratus menores de hipotensão, altera a PIO de forma pouco signilicativa cuando comparadat a seus congêneres (MII.I.I:R? 1981 ). 


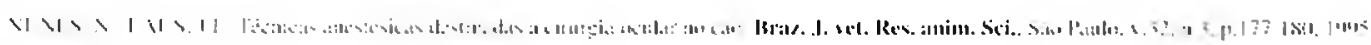

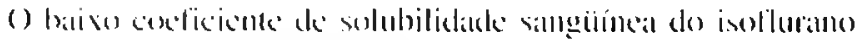

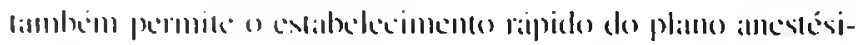

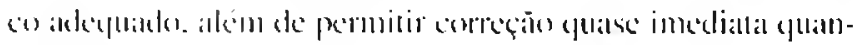

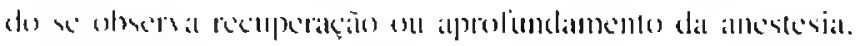
(2I1 momentor menos com

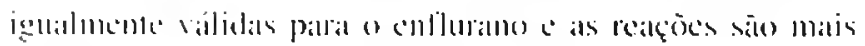

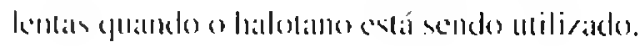

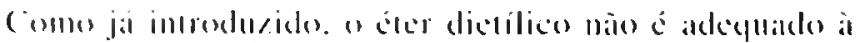

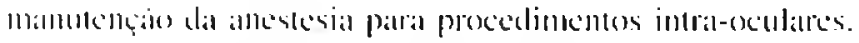

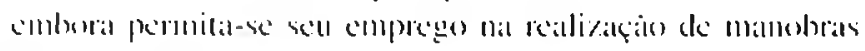
endri-erulatis.

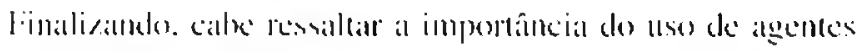

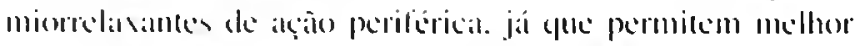
commole da posiçân do bulbo a medida que relaxam a mus-

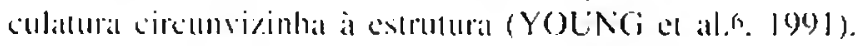
Neste patricular pode-sc optall pelo antacúrio ou pancurônio.

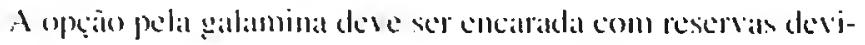

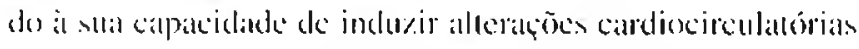

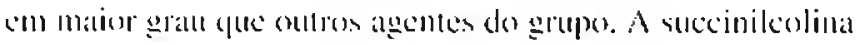

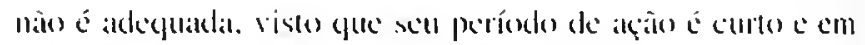
caso cmergencial hior a possivel a reversio do sell efeito misrrelaxamtr.

\section{CONCIJUSOLS}

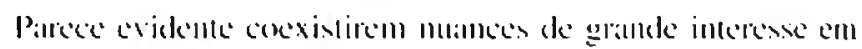

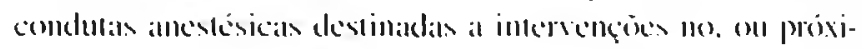
mas. an glabo ocular. A litrrallura mostrat-se cscassil. dificul-

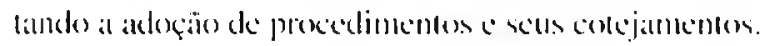

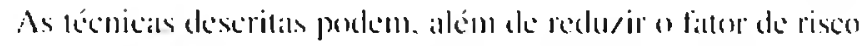

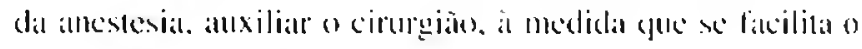
acesso às estruturats a serem explubialas.

Fimalmente obriga-xe esclatecer an prolissional. o respeito ao paciente, às sllats condiçós clínicas e a necessária

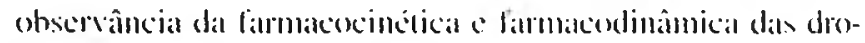

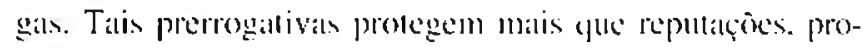
tegem vidlas.

\section{SLMIMIRY}

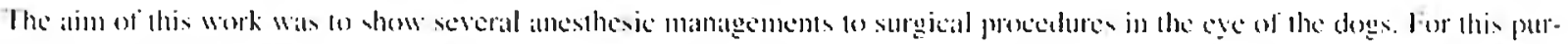

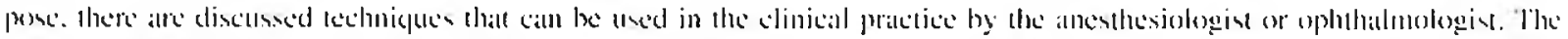

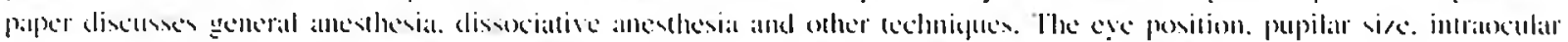

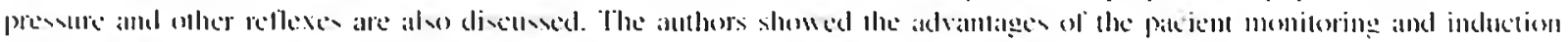
kobitpus.

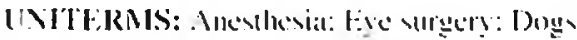

\section{RIFEKRENCIAS BIBI.IOGRÍFICAS}

I (il.I.ATT. K.V. Veterinary ophlalumology. 2.ed.

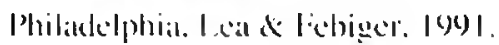

2-MASSONI: J. Anestesiologia veterinaria.

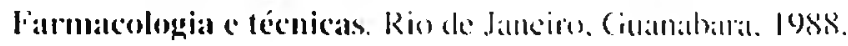

3-MII.I.t:R. R.D). Aneshlosia. New York. Churchill l.isin!ustome. I0sil.

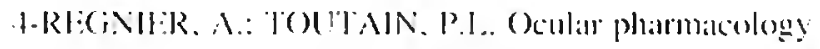
and derapentic modalitien. In: (iEI AJT. K.N. Velerinary

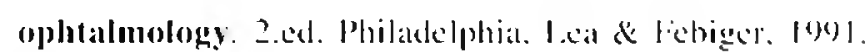
(:1). 3. 1.16294.

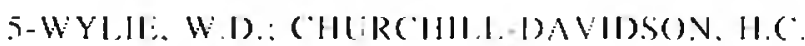
Anestesiologia. i.e(l. Rio do Jankeito, (inallalhallia. 1974.

G-YOING. S.S.: BARNETI. K.C. TAYLOR. P.M

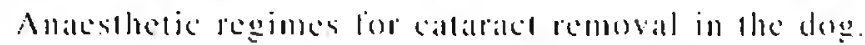
Jourmal of Small Animal Practice. 1.32. p.230-40. | (y)|

Recel)ido para publica(̨ão (em 03/12/9)4 Aprovado para publicação em 13/12/94 